\title{
A EUROPEAN MEETING ON RED CROSS INFORMATION
}

The need for the Red Cross the better to adapt itself to present information requirements and public relations was the principal reason for the Conference held in Geneva from January 25 to 27, 1967 in which twelve European National Societies participated (Belgium, Denmark, France, German Democratic Republic, German Federal Republic, Great Britain, Greece, Italy, Netherlands, Poland, Switzerland and Yugoslavia). Other Societies of the continent expressed their approval and interest in the meeting and the projected exchanges of views even if they were unable to be present. The ICRC had taken the initiative in convening the Conference and ensured its preparation and organization jointly with the League, at whose headquarters part of the work also took place.

The first item on the agenda dealt with the " position and rôle of information in the Red Cross world on the international and national levels". The preliminary commentary, prepared by the ICRC and the League included this remark on the subject: "Our meeting should be the occasion of reconsidering the whole problem of Red Cross public relations, a problem whose great importance does not always appear to be fully appreciated."

In this respect, it appears that the Conference really achieved the desired objective, since it first of all enabled the heads of information present to be more clearly aware of the extent and multiplicity of the tasks devolving on them. It also brought out the necessity of obtaining closer co-operation between the information bodies of the international institutions of the Red Cross in Geneva and those of the National Societies. In this connection, the meeting was a particularly welcome occasion for comparing the information methods in use in various countries. This in itself, by making contact will no doubt already have had a stimulating effect on those in charge of this field of activity. 


\section{IN THE Red Cross World}

The need of redoubling efforts here was also clearly apparent in exchanges of views on the present popularity of the Red Cross and on the "competition" it encounters from other organizations carrying out activities close to it. Several speakers in particular stressed the urgency of interesting the young and associating them with the work of our Societies, for, being constantly pressed from all directions, the young are liable to turn away from the Red Cross and no longer to understand the possibilities it offers to their enthusiasm.

Other items on the agenda were as follows: 2. Dissemination of Information. 3. Radio problems. 4. Commemoration of World Red Cross Day. 5. Television. 6. Graphic representation. 7. Dissemination of documents and publications of National Societies and of the international institutions of the Red Cross. 8. Dissemination of the Geneva Conventions and Red Cross principles.

This list shows that all the main problems connected with Red Cross information were reviewed. These problems, unfortunately, are generally of such amplitude that it was not possible to deal with them with sufficient thoroughness. The discussions will however have been of great usefulness in different respects.

In addition to the new ideas expressed of which the participants will have made an abundant harvest thanks to the variety of experiences and opinions exchanged, the talks enabled a series of practical measures to be envisaged as regards co-operation which is even more necessary. Such co-operation can present the triple advantage of increasing the quality and the quantity of information whilst decreasing its cost. The views exchanged also gave the opportunity of pointing out certain errors and clumsiness in dealing with the public and indicating remedies.

There was specially wide-ranging discussion on television to which, in the general view, the Red Cross should resort more often. For the ICRC and the League this was the occasion to collect valuable data on the best method of adapting their information material to the needs of National Societies and the European public.

This Conference which will have owed its success to the active participation of National Societies and the balanced observations of their representatives will be the subject of a report which will 
shortly be made available. This summary will contain a list of the principal points discussed and in particular of the wishes expressed with a view to improving the information work of the Red Cross, in other words, to increasing the extent and effectiveness of our movement.

In fact, it should be stressed that the participants' main preoccupation was effectiveness, for it was not necessary to remind these professionals of information and public relations that the importance of this sphere of activity is continuously increasing in the world today. However, one should also mention the interest which this meeting and its work had for all members of the Red Cross, where it has not always been sufficiently understood that often, in order to give more effective aid, one should begin by giving better information.

R. D.P.

\section{THE FUTURE OF THE RED CROSS}

In one of the latest issues of The Red Cross World ${ }^{1}$ are to be found various illustrated articles on problems which the Red Cross will no doubt have to contend with in years to come and on nere methods and techniques which it uses and will continue to use more and more to ensure the greater rapidity and effectiveness of its work. In his foreword, Mr. José Barroso, League Chairman, draws attention to the need for the Red Cross to adapt to a world which is visibly undergoing radical changes.

Other articles deal with such subjects as "The effect of the transistor evolution", "Automation and the Red Cross", "Satellites already important to Red Cross work", "Closed circuit television", "The population explosion-its meaning for Red Cross" and finally in the article which we quote below, Mr. Henry $W$. Dunning, former League

1 No. 3, Geneva, 1966. 